\title{
Effectiveness of Gastric Bypass Versus Gastric Sleeve for Cardiovascular Disease: Protocol and Baseline Results for a Comparative Effectiveness Study
}

Karen J Coleman ${ }^{1}$, BS, PhD; Heidi Fischer ${ }^{1}$, PhD; David E Arterburn ${ }^{2}$, MD, MPH; Douglas Barthold ${ }^{3}$, PhD; Lee J Barton $^{1}, \mathrm{MS}$; Anirban Basu ${ }^{3}, \mathrm{PhD}$; Anita Courcoulas ${ }^{4}, \mathrm{MD}$; Cecelia L Crawford ${ }^{5}$, DNP, RN; Peter Fedorka ${ }^{6}$, MD; Benjamin $\mathrm{Kim}^{7}$, MD; Edward Mun ${ }^{7}$, MD; Sameer Murali ${ }^{8}$, MD; Kristi Reynolds ${ }^{1}$, PhD; Kangho Suh ${ }^{3}$, PharmD; Rong $\mathrm{Wei}^{1}$, MS; Tae K Yoon ${ }^{1}$, MS; Robert Zane ${ }^{7}$, MD

\footnotetext{
${ }^{1}$ Department of Research and Evaluation, Kaiser Permanente Southern California, Pasadena, CA, United States

${ }^{2}$ Health Research Institute, Kaiser Permanente Washington, Seattle, WA, United States

${ }^{3}$ The Comparative Health Outcomes, Policy, and Economics Institute, Department of Pharmacy, University of Washington, Seattle, WA, United States

${ }^{4}$ Department of Surgery, School of Medicine, University of Pittsburgh, Pittsburgh, PA, United States

${ }^{5}$ Regional Nursing Research Program, Kaiser Permanente Southern California, Pasadena, CA, United States

${ }^{6}$ Department of Surgery, San Bernardino Medical Center, Kaiser Permanente Southern California, Ontario, CA, United States

${ }^{7}$ Department of Surgery, South Bay Medical Center, Kaiser Permanente Southern California, Harbor City, CA, United States

${ }^{8}$ Center for Healthy Living, San Bernardino Medical Center, Kaiser Permanente Southern California, Fontana, CA, United States
}

\section{Corresponding Author:}

Karen J Coleman, BS, PhD

Department of Research and Evaluation

Kaiser Permanente Southern California

100 S Los Robles

Pasadena, CA

United States

Phone: 16265643580

Email: Karen.J.Coleman@kp.org

\section{Abstract}

Background: When compared with conventional weight loss strategies, bariatric surgery results in substantially greater durable weight loss and rates of disease remission.

Objective: The ENGAGE CVD (Effectiveness of Gastric Bypass versus Gastric Sleeve for Cardiovascular Disease) cohort study aimed to provide population-based, comprehensive, rigorous evidence for clinical and policy decision making regarding the choice between gastric bypass and gastric sleeve for overall cardiovascular disease (CVD) risk reduction, risk factor remission, and safety.

Methods: The cohort had 22,095 weight loss surgery patients from a large integrated health care system in Southern California assembled from 2009 to 2016 who were followed up through 2018. Bariatric surgery patients were followed up for the length of their membership in the health care system. Of the patients who had at least five years of follow-up (surgery between 2009 and 2013), 85.86\% (13,774/16,043) could contribute to the outcome analyses for the ENGAGE CVD cohort.

Results: Patients in the ENGAGE CVD cohort were 44.6 (SD 11.4) years old, mostly women (17,718/22,095; 80.19\%), with $18.94 \%(4185 / 22,095)$ non-Hispanic black and 41.80\% (9235/22,095) Hispanic, and had an average BMI of 44.3 (SD 6.9) kg/m² at the time of surgery. When compared with patients who did not contribute data to the 5-year outcome analysis for the ENGAGE CVD cohort $(2269 / 16,043 ; 14.14 \%)$, patients who contributed data $(13,774 / 16,043 ; 85.86 \%)$ were older $(P=.002)$, more likely to be women $(P=.02)$, more likely to be non-Hispanic white $(P<.001)$, more likely to have had an emergency department visit in the year before surgery $(P=.006)$, less likely to have a mental illness before surgery $(P<.001)$, and more likely to have had a CVD event at any time before surgery $(P<.001)$.

Conclusions: This study had one of the largest populations of gastric sleeve patients $(n=13,459)$. The 5-year follow-up for those patients who had surgery between 2009 and 2013 was excellent for a retrospective cohort study at 85.86\% (13,774/16,043). 
Unlike almost any study in the literature, the majority of the ENGAGE CVD cohort was racial and ethnic minority, providing a rare opportunity to study the effects of bariatric surgery for different racial and ethnic groups, some of whom have the highest rates of severe obesity in the United States. Finally, it also used state-of-the-art statistical and econometric comparative effectiveness methods to mimic the effect of random assignment and control for sources of confounding inherent in large observational studies.

International Registered Report Identifier (IRRID)： RR1-10.2196/14936

(JMIR Res Protoc 2020;9(4):e14936) doi: 10.2196/14936

\section{KEYWORDS}

race; weight loss surgery; integrated health care system

\section{Introduction}

\section{Overview of Surgical Treatment for Severe Obesity}

The prevalence of severe obesity (BMI $>35 \mathrm{~kg} / \mathrm{m}^{2}$ ) has increased over the past several decades. Rates are as high as $36 \%$ for middle-aged black women compared with $16 \%$ for their white counterparts in the United States [1]. Even with intensive, multicomponent lifestyle interventions, only $50 \%$ of studies show $5 \%$ weight loss (considered clinically meaningful), and most of the participants gain back at least half of this lost weight over 18 to 30 months [2]. These poor outcomes have resulted in the development of surgical treatments, referred to as bariatric surgery, for severe obesity. When compared with conventional weight loss strategies, bariatric surgery results in seven times the amount of weight loss and 15.8 times the rate of diabetes remission [3], and these differences remain up to 5 years [4,5]. Given the poor results from traditional weight loss methods [2], and the designation of obesity as a disease [6], bariatric surgery may become a more common treatment of choice for adults with severe obesity.

Two surgical treatments constitute most bariatric operations in the United States: vertical sleeve gastrectomy (VSG) and Roux-en-Y gastric bypass (RYGB). VSG, in which stomach size is reduced, was initially performed as the first part of a multistage procedure in 2000 . RYGB, in which gastric capacity is also limited but with an additional bypass of the first few feet of small intestine, was first performed in 1994 [7]. VSG has emerged as the fastest growing bariatric operation in the United States. Between 2008 and 2014, there was a dramatic increase in VSGs from $4 \%$ to $51 \%$ of all bariatric operations, whereas RYGB declined from $51 \%$ to $27 \%$ [8]. The reasons for this shift have not been systematically studied, but based upon our own work [9], it is likely because of patients' and surgeons' perceptions that although VSG and RYGB have similar weight loss and disease remission, VSG is easier to perform with fewer complications compared with RYGB.

\section{Evidence for Comparative Effectiveness of Surgical Treatments}

Unfortunately, the use of VSG has outpaced a rigorous evidence base for its comparative effectiveness to RYGB [10-15]. In addition, few large population-based studies in real-world health care settings have adequate methodological rigor to account for the fact that VSG and RYGB operations are not randomly assigned. Patients with risk factors for cardiovascular disease (CVD), especially type 2 diabetes mellitus (T2DM), are more likely to undergo RYGB [16]. The reasons for this are not clear; however, it is likely that surgeons and patients believe RYGB is more effective than VSG for resolving T2DM. If this treatment choice preference is not accounted for in the analyses, then erroneous conclusions could be made about the effectiveness of one operation compared with another because the patients receiving each treatment are different in ways that also affect the outcome.

\section{Addressing Limitations in the Evidence Base}

Rigorous statistical methods such as matching, propensity scores, and/or instrumental variables have only been applied to the study of the comparative effectiveness of VSG and RYGB in the remission and relapse of T2DM. To our knowledge, there have been no rigorous comparative effectiveness studies published for other risk factors for CVD, including hypertension and dyslipidemia. In addition, there are no published studies on the comparative effectiveness of VSG and RYGB for reducing overall CVD risk beyond the first year after surgery. The ENGAGE CVD (Effectiveness of Gastric Bypass versus Gastric Sleeve for Cardiovascular Disease) cohort study was funded by the National Heart, Lung, and Blood Institute to provide population-based, comprehensive, rigorous evidence for clinical and policy decision making regarding the choice between RYGB and VSG for overall CVD risk reduction, risk factor remission, and safety. The ENGAGE CVD study uses state-of-the-art statistical and econometric comparative effectiveness methods, including propensity scores and local instrumental variables (LIVs), to mimic the effect of random assignment and control for sources of both observed and unobserved confounding inherent in large observational studies.

\section{Study Objectives and Hypotheses}

There were three aims for the ENGAGE CVD study. Aim 1 compared the effectiveness of VSG and RYGB in remission and relapse of CVD risk factors and reduction in overall CVD risk. For this aim we hypothesized that RYGB patients would experience a higher rate of T2DM, hypertension, and dyslipidemia remission and lower rate of relapse compared with VSG patients. RYGB patients would also have a greater reduction in overall CVD risk. Aim 2 compared VSG and RYGB surgical safety. We hypothesized that VSG patients would have better short- and long-term safety outcomes than RYGB patients. Aim 3 was designed to understand the treatment effect heterogeneity in remission and relapse of CVD risk factors, reduction in overall CVD risk, and safety outcomes for patients with different racial and ethnic backgrounds, genders, ages, and disease burdens at the time of surgery. Based upon our own work in this area, we expected an interaction of racial and ethnic 
minority, male sex, older age, and having a higher disease burden in attenuating the differences hypothesized between RYGB and VSG.

\section{Methods}

\section{Settings and Participants}

Figure 1 shows the process of selecting the ENGAGE CVD cohort $(n=22,095)$ and Table 1 presents descriptive statistics for the RYGB and VSG patients in the cohort. The cohort was assembled from 2009 to 2016 from a large integrated health care system serving the Southern California region of the United States. This health care system had 4.2 million members, 14 hospitals, 200 medical offices, 5700 physicians, and 23 bariatric surgeons at the time the cohort was assembled. Inclusion and exclusion criteria for the ENGAGE CVD cohort are shown in Figure 1.

Figure 1. Inclusion and exclusion criteria for the ENGAGE CVD (Effectiveness of Gastric Bypass versus Gastric Sleeve for Cardiovascular Disease) cohort study. RYGB: Roux-en-Y gastric bypass; VSG: vertical sleeve gastrectomy.

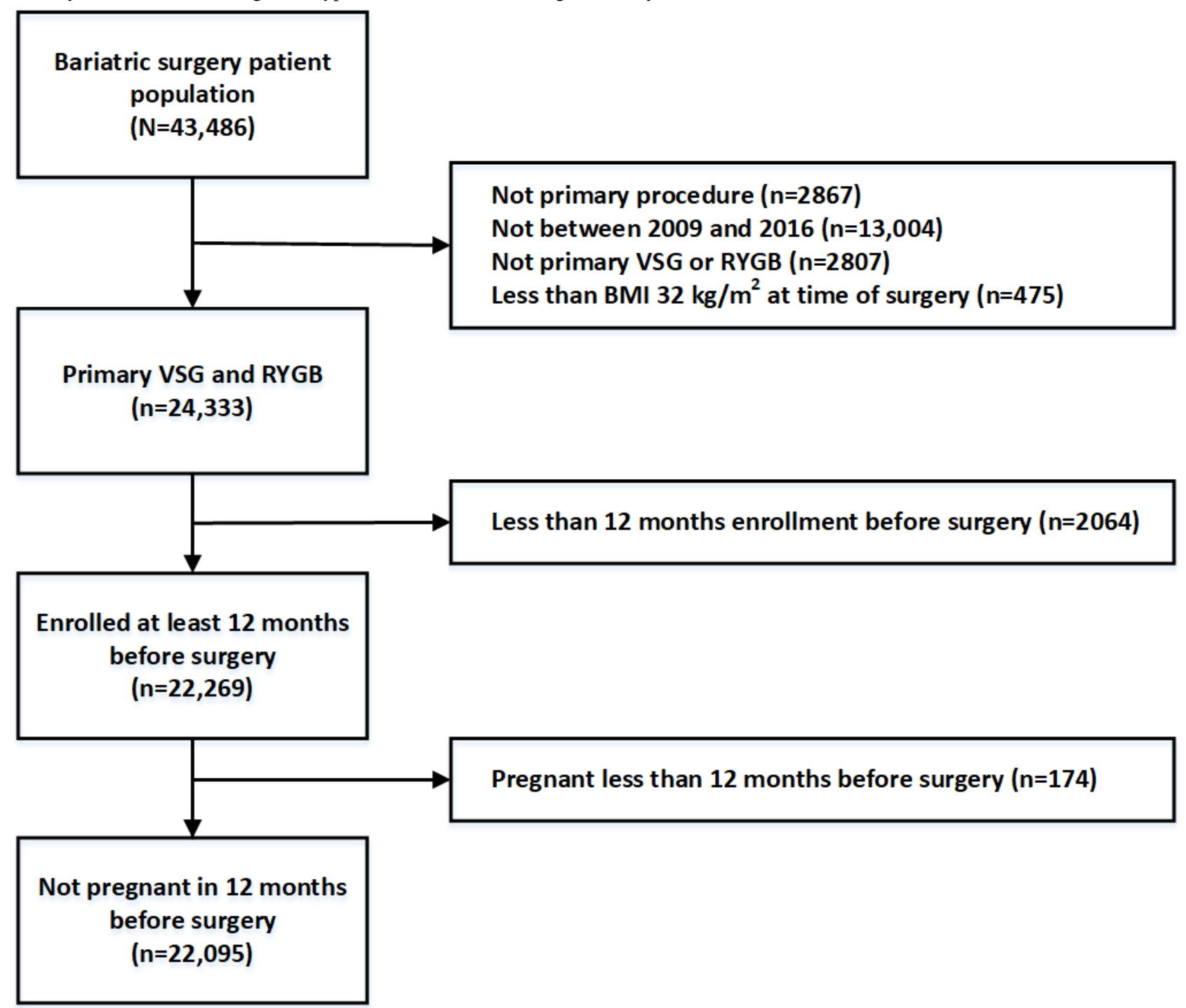

This cohort of bariatric surgery patients was similar to other bariatric studies published in the United States, with the exception that there was a much higher proportion of ethnic/racial minorities $(63.8 \%)$ than in other published work $[17,18]$. Eligibility for weight loss surgery in this health care system was based upon national recommendations [19]: Having a BMI $\geq 40 \mathrm{~kg} / \mathrm{m}^{2}$ or having a BMI of $35-39 \mathrm{~kg} / \mathrm{m}^{2}$ and at least one obesity-related comorbid condition such as sleep apnea, T2DM, and heart disease. Patients meeting these criteria could still be refused surgery if the surgeon determined that the patient had excessively high medical risk for surgery and in some cases, patients could have surgery if their BMI was as low as $32 \mathrm{~kg} / \mathrm{m}^{2}$ with T2DM. Only $3.66 \%(808 / 22,095)$ of the ENGAGE CVD cohort had a BMI of $32-34.99 \mathrm{~kg} / \mathrm{m}^{2}$ at the time of their operation.

\section{Measures}

Bariatric surgery patients were followed up for the length of their membership in the health care system. Weight, height, and blood pressure were measured at every outpatient visit. In general, laboratory measures relevant to CVD such as glucose and glycated hemoglobin $\left(\mathrm{HbA}_{1 \mathrm{c}}\right)$ were measured before surgery and at least annually following surgery. Lipids were only measured routinely every 5 years following national screening 
guidelines [20]. All data were abstracted from the electronic health record for the period of 2009 to 2018 and comprised the following broad categories of information.

\section{Baseline}

At the time of surgery, patient self-reported date of birth, gender, and race/ethnicity were obtained. Details of surgery type, surgeon, and surgery location were also assembled for the cohort.

\section{Baseline and Follow-Up}

Data were obtained for 24 months before the date of surgery and up to 10 years after surgery and included the following: (1) Dates and status of health care system enrollment and types of insurance coverage including pharmacy coverage; (2) vital signs such as height, weight, and blood pressure (in general, height was self-reported, and weight and blood pressure were measured by clinical staff at every outpatient visit. Previous research in health care settings has demonstrated that heights and weights from electronic medical records are valid and suitable for research [21]. Most blood pressure measurements were performed by certified medical assistants using automatic devices.); (3) self-reported smoking status from outpatient visits; (4) comprehensive prescription data for each drug dispensed at health care system pharmacies and all outpatient and inpatient laboratory results were also available (almost all patients [>96\%] had benefits that incentivized the use of health care system pharmacies and laboratories); (5) all dates and types of health care utilization for inpatient, emergency department, and outpatient settings (including external claims data from contracted surgical providers); and (6) the diagnoses and procedures associated with this health care utilization.

\section{Outcomes}

The primary outcome for the first aim of the ENGAGE CVD study was T2DM remission and relapse in each of the years of follow-up after bariatric surgery up to 5 years. Secondary outcomes for aim 1 were hypertension and dyslipidemia remission and relapse, and overall 10-year CVD risk as assessed with the new American College of Cardiology and the American Heart Association guidelines, referred to as the Pooled Cohort Equations Risk Calculator or ASCVD risk score [22], over this same time period. The primary outcome for aim 2 was a 30-day composite measure of major adverse events specific to bariatric surgery patients. The secondary outcomes for aim 2 were long-term annual rates of reoperations/revisions, readmissions, emergency department use, and all-cause mortality up to 5 years following bariatric surgery.

\footnotetext{
Analyses

Summary statistics for the ENGAGE CVD cohort were generated using means and standard deviations for continuous variables and frequency and percent for categorical variables. Unadjusted differences between patients who were alive and still members of the health care system 5 years after surgery $(n=13,774)$ and those patients who were not $(n=2269)$, as well as between patients who had RYGB $(n=8636)$ and VSG $(n=13,459)$ were analyzed with independent sample $t$ tests
}

(continuous); and the Chi-square statistic and Kruskal-Wallis test (categorical).

The main analysis for the outcomes was a LIV approach [23]. This approach used a continuous instrumental variable to estimate the effect on every margin of the patient population and estimated population average effects to understand how different patients did with different treatments. This is referred to as heterogeneity of treatment effects (HTE) [24]. A clinically intuitive description of these methods applied to a clinical setting has been recently published [25]. These findings were compared with more traditional comparative effectiveness methods in retrospective observational studies, such as inverse-probability weighted propensity score regression [26], that only controlled for observed confounders in the decision between VSG and RYGB operations.

\section{Results}

\section{Participants}

Descriptive characteristics for patients in the ENGAGE CVD cohort are shown in Table 1. Overall, the cohort was 44.6 (SD $11.35)$ years old, with $80.19 \%(17,718 / 22,095)$ women, $18.94 \%$ $(4185 / 22,095)$ non-Hispanic blacks, and $41.80 \%(9235 / 22,095)$ Hispanics. Patients had an average BMI of 44.30 (SD 6.88) $\mathrm{kg} / \mathrm{m}^{2}$ at surgery with the majority having a BMI between $35-50$ $\mathrm{kg} / \mathrm{m}^{2}(17,386 / 22,095 ; 78.69 \%)$. In the 2 years before surgery, patients had been diagnosed with the following conditions: $36.56 \%(8078 / 22,095)$ gastroesophageal reflux disease (GERD), $15.48 \%(3421 / 22,095)$ sleep apnea, $36.72 \%(8114 / 22,095)$ T2DM, $53.80 \%(11,887 / 22,095)$ hypertension, $72.82 \%$ (16,090/22,095; dyslipidemia, and 11,967/22,095; $54.16 \%$ mental health condition (primarily depression). Only $3.44 \%$ $(759 / 22,095)$ had a CVD event in their lifetime before surgery.

\section{Missing Data}

Of the 22,095 patients in the ENGAGE CVD cohort, 16,043 (72.61\%) had surgery between 2009 and 2013 and thus had enough follow-up time for the assessment of outcomes at 5 or more years following surgery. Of these 16,043 patients, 13,774 $(85.86 \%)$ were still living (104 died before 5 years) and members of the health plan (2165 discontinued membership 5 years after surgery) at 5 years after surgery. Table 2 presents differences in baseline data for the ENGAGE CVD cohort of patients who were alive and still members of the health care system 5 years after surgery $(n=13,774)$ compared with those patients who were not $(n=2269)$. When compared with patients who did not contribute data to the 5-year outcome analysis for the ENGAGE CVD cohort $(2269 / 16,043 ; 14.14 \%)$, patients who contributed data $(13,774 / 16,043 ; 85.86 \%)$ were older $(P=.002)$, more likely to be women $(P=.02)$, more likely to be non-Hispanic white $(P<.001)$, more likely to have a duodenal ulcer at the time of surgery $(P<.001)$, less likely to have dyslipidemia $(P<.001)$, more likely to have had an emergency department visit in the year before surgery $(P=.006)$, less likely to have a mental illness before surgery $(P<.001)$, and more likely to have had a CVD event at any time before surgery $(P<.001)$. 
Table 1. Characteristics of patients before surgery who are included in the ENGAGE CVD (Effectiveness of Gastric Bypass versus Gastric Sleeve for Cardiovascular Disease) cohort study $(\mathrm{n}=22,095)$ by bariatric operation (vertical sleeve gastrectomy [VSG] and Roux-en-Y gastric bypass [RYGB]. Characteristics at the time of surgery are compared between VSG and RYGB.

\begin{tabular}{|c|c|c|c|c|}
\hline Characteristics & Overall $(n=22,095)$ & $\operatorname{VSG}^{\mathrm{a}}(\mathrm{n}=13,459)$ & RYGB $^{\mathrm{b}}(\mathrm{n}=8636)$ & $P$ value \\
\hline Age years), mean (SD) & $44.6(11.35)$ & $44.1(11.39)$ & $45.4(11.25)$ & $<.001$ \\
\hline Women, n (\%) & $17,718(80.19)$ & $10,850(80.62)$ & $6868(79.53)$ & .06 \\
\hline Non-Hispanic black, n (\%) & $4185(18.94)$ & $2886(21.44)$ & $1299(15.04)$ & $<.001$ \\
\hline Hispanic, n (\%) & $9235(41.80)$ & $5576(41.43)$ & $3659(42.37)$ & $<.001$ \\
\hline Non-Hispanic white, $\mathrm{n}(\%)$ & $7997(36.19)$ & $4599(34.17)$ & $3398(39.35)$ & $<.001$ \\
\hline Other, $\mathrm{n}(\%)$ & $678(3.07)$ & $398(2.96)$ & $280(3.24)$ & $<.001$ \\
\hline Weight loss in the year before surgery (lbs), mean (SD) & $-17.2(14.74)$ & $-17.8(14.53)$ & $-16.4(15.02)$ & $<.001$ \\
\hline BMI at surgery $\left(\mathrm{kg} / \mathrm{m}^{2}\right)$, mean (SD) & $44.3(6.88)$ & $43.8(6.63)$ & $45.1(7.17)$ & $<.001$ \\
\hline BMI $32-34.99 \mathrm{~kg} / \mathrm{m}^{2}$ at surgery, $\mathrm{n}(\%)$ & $808(3.66)$ & $547(4.06)$ & $261(3.02)$ & $<.001$ \\
\hline BMI $35-39.99 \mathrm{~kg} / \mathrm{m}^{2}$ at surgery, $\mathrm{n}(\%)$ & $5531(25.03)$ & $3633(26.99)$ & $1898(21.98)$ & $<.001$ \\
\hline BMI $40-49.99 \mathrm{~kg} / \mathrm{m}^{2}$ at surgery, $\mathrm{n}(\%)$ & $11,856(53.66)$ & $7185(53.38)$ & $4671(54.09)$ & $<.001$ \\
\hline $\mathrm{BMI}>50 \mathrm{~kg} / \mathrm{m}^{2}$ at surgery, $\mathrm{n}(\%)$ & $3900(17.65)$ & $2094(15.56)$ & $1806(20.91)$ & $<.001$ \\
\hline Any lifetime cardiovascular disease event before surgery, $\mathrm{n}(\%)$ & $759(3.44)$ & $421(3.13)$ & $338(3.91)$ & .002 \\
\hline Gastroesophageal reflux disease in 2 years before surgery, $\mathrm{n}(\%)$ & $8078(36.56)$ & $4472(33.23)$ & $3606(41.76)$ & $<.001$ \\
\hline Esophagitis in 2 years before surgery, $\mathrm{n}(\%)$ & $388(1.76)$ & $217(1.61)$ & $171(1.98)$ & .04 \\
\hline Gastric ulcer in 2 years before surgery, $\mathrm{n}(\%)$ & $153(0.07)$ & $96(0.071)$ & $57(0.07)$ & .64 \\
\hline Duodenal ulcer in 2 years before surgery, $\mathrm{n}(\%)$ & $1411(6.39)$ & $816(6.06)$ & $595(6.89)$ & .01 \\
\hline Peptic ulcer in 2 years before surgery, $\mathrm{n}(\%)$ & $346(1.57)$ & $197(1.46)$ & $149(1.73)$ & .13 \\
\hline Gastritis duodenitis in 2 years before surgery, $\mathrm{n}(\%)$ & $2538(11.49)$ & $1518(11.28)$ & $1020(11.81)$ & .23 \\
\hline Dyspepsia in 2 years before surgery, $\mathrm{n}(\%)$ & $2625(11.88)$ & $1614(11.99)$ & $1011(11.71)$ & .52 \\
\hline Hiatal hernia in 2 years before surgery, $\mathrm{n}(\%)$ & $688(3.11)$ & $382(2.84)$ & $306(3.54)$ & .003 \\
\hline Gastrointestinal bleed in 2 years before surgery, $\mathrm{n}(\%)$ & $9(0.00)$ & $5(0.00)$ & $4(0.00)$ & .74 \\
\hline Aspirin use in 1 year before surgery, $\mathrm{n}(\%)$ & $3925(17.76)$ & $1875(13.93)$ & $2050(23.74)$ & $<.001$ \\
\hline Aspirin use in 3 months before surgery, $\mathrm{n}(\%)$ & $2517(11.39)$ & $1255(9.32)$ & $1262(14.61)$ & $<.001$ \\
\hline NSAID $^{c}$ use in 1 year before surgery, $n(\%)$ & $9630(43.58)$ & $5916(43.96)$ & $3714(43.01)$ & .17 \\
\hline NSAID use in 3 months before surgery, $\mathrm{n}(\%)$ & $3260(14.75)$ & $1985(14.75)$ & $1275(14.76)$ & .975 \\
\hline Cirrhosis in 2 years before surgery, $\mathrm{n}(\%)$ & $122(0.01)$ & $77(0.01)$ & $45(0.01)$ & 62 \\
\hline Sleep apnea in 2 years before surgery, $\mathrm{n}(\%)$ & $3421(15.48)$ & $1983(14.73)$ & $1438(16.65)$ & $<.001$ \\
\hline Type 2 diabetes mellitus in 2 years before surgery, $\mathrm{n}(\%)$ & $8114(36.72)$ & $3827(28.43)$ & $4287(49.64)$ & $<.001$ \\
\hline Hypertension in 2 years before surgery, $\mathrm{n}(\%)$ & $11,887(53.80)$ & $6704(49.81)$ & $5183(60.01)$ & $<.001$ \\
\hline Chronic kidney disease in 2 years before surgery, $\mathrm{n}(\%)$ & $2623(11.87)$ & $1402(10.42)$ & $1221(14.14)$ & $<.001$ \\
\hline Dyslipidemia in 2 years before surgery, $\mathrm{n}(\%)$ & $16,090(72.82)$ & $9409(69.90)$ & $6681(77.36)$ & $<.001$ \\
\hline Any mental health condition in 2 years before surgery, $\mathrm{n}(\%)$ & $11,967(54.16)$ & $7153(53.15)$ & $4814(55.74)$ & $<.001$ \\
\hline Attendance rate in 1 year before surgery (range $0 \%-100 \%$ ), mean (SD) & $76.60(12.39)$ & $76.30(12.31)$ & $77.00(12.49)$ & $<.001$ \\
\hline Any inpatient visit 1 year before surgery, $\mathrm{n}(\%)$ & $1317(5.96)$ & $722(5.36)$ & $595(6.89)$ & $<.001$ \\
\hline Any emergency department visit in 1 year before surgery, $\mathrm{n}(\%)$ & $4655(21.07)$ & $2788(20.71)$ & $1867(21.62)$ & .11 \\
\hline
\end{tabular}

${ }^{\mathrm{a}}$ VSG: vertical sleeve gastrectomy.

${ }^{\mathrm{b}} \mathrm{RYGB}$ : Roux-en-Y gastric bypass.

${ }^{\mathrm{c}}$ NSAID: nonsteroidal anti-inflammatory drug. 
Table 2. Characteristics of patients before surgery in the ENGAGE CVD (Effectiveness of Gastric Bypass versus Gastric Sleeve for Cardiovascular Disease) cohort study who accumulated 5 years of follow-up after surgery $(\mathrm{n}=16,043)$. Findings are compared for those patients who had missing $(2269 / 16,043 ; 14.14 \%)$ and no missing $(13,774 / 16,043 ; 85.86 \%)$ data at 5 years following bariatric surgery.

\begin{tabular}{|c|c|c|c|c|}
\hline Variables & $\begin{array}{l}\text { Accumulated } 5 \text { years of } \\
\text { follow-up }(\mathrm{N}=16,043)\end{array}$ & Missing 5-year data $(\mathrm{N}=2269)$ & $\begin{array}{l}\text { Complete 5-year data } \\
(\mathrm{N}=13,774)\end{array}$ & $P$ value \\
\hline Roux-en-Y gastric bypass, $\mathrm{n}(\%)$ & $6891(42.95)$ & $1104(48.66)$ & $5787(42.01)$ & $<.001$ \\
\hline Vertical sleeve gastrectomy, n (\%) & $9152(57.05)$ & $1165(51.34)$ & 7987 (57.99) & $<.001$ \\
\hline Age (years), mean (SD) & $44.1(11.92)$ & $45.0(9.54)$ & $44.0(12.26)$ & .002 \\
\hline Women, n (\%) & $12,860(80.16)$ & $1779(78.40)$ & $11,081(80.45)$ & .02 \\
\hline Non-Hispanic black, n (\%) & $3067(19.12)$ & $375(16.52)$ & $2692(19.54)$ & $<.001$ \\
\hline Hispanic, n (\%) & $6470(40.33)$ & $922(40.64)$ & $5548(40.28)$ & $<.001$ \\
\hline Non-Hispanic white, $\mathrm{n}(\%)$ & $6011(37.47)$ & $929(40.94)$ & $5082(36.90)$ & $<.001$ \\
\hline Other, $\mathrm{n}(\%)$ & $495(3.09)$ & $43(1.90)$ & $452(3.28)$ & $<.001$ \\
\hline $\begin{array}{l}\text { Weight loss in year before surgery (lbs), } \\
\text { mean (SD) }\end{array}$ & $-16.9(15.01)$ & $-17.3(14.94)$ & $-16.9(15.02)$ & .04 \\
\hline BMI at surgery $\left(\mathrm{kg} / \mathrm{m}^{2}\right)$, mean $(\mathrm{SD})$ & $44.7(6.95)$ & $44.8(7.17)$ & $44.6(6.91)$ & .59 \\
\hline BMI $32-34.99 \mathrm{~kg} / \mathrm{m}^{2}$ at surgery, $\mathrm{n}(\%)$ & $508(3.17)$ & $69(3.04)$ & $439(3.19)$ & .84 \\
\hline BMI $35-39.99 \mathrm{~kg} / \mathrm{m}^{2}$ at surgery, $\mathrm{n}(\%)$ & $3701(23.07)$ & $516(22.74)$ & $3185(23.12)$ & .84 \\
\hline BMI $40-49.99 \mathrm{~kg} / \mathrm{m}^{2}$ at surgery, $\mathrm{n}(\%)$ & $8818(54.96)$ & $1243(54.78)$ & $7575(55.00)$ & .84 \\
\hline $\mathrm{BMI}>50 \mathrm{~kg} / \mathrm{m}^{2}$ at surgery, $\mathrm{n}(\%)$ & $3016(18.80)$ & $441(19.44)$ & $2575(18.69)$ & .40 \\
\hline $\begin{array}{l}\text { Any lifetime cardiovascular disease event } \\
\text { before surgery, } \mathrm{n}(\%)\end{array}$ & $759(4.73)$ & $0(0.00)$ & $759(5.51)$ & $<.001$ \\
\hline $\begin{array}{l}\text { Gastroesophageal reflux disease in } 2 \text { years } \\
\text { before surgery, } \mathrm{n}(\%)\end{array}$ & $5799(36.15)$ & $800(35.26)$ & $4999(36.29)$ & .34 \\
\hline Esophagitis in 2 years before surgery, $\mathrm{n}(\%)$ & $281(1.75)$ & $33(1.45)$ & $248(1.80)$ & .24 \\
\hline $\begin{array}{l}\text { Gastric ulcer in } 2 \text { years before surgery, } \mathrm{n} \\
(\%)\end{array}$ & $108(0.07)$ & $18(0.08)$ & $90(0.07)$ & .45 \\
\hline $\begin{array}{l}\text { Duodenal ulcer in } 2 \text { years before surgery, } \\
\mathrm{n}(\%)\end{array}$ & $1089(6.79)$ & $108(4.76)$ & $981(7.12)$ & $<.001$ \\
\hline Peptic ulcer in 2 years before surgery, $\mathrm{n}(\%)$ & $264(1.65)$ & $39(1.72)$ & $225(1.63)$ & .77 \\
\hline $\begin{array}{l}\text { Gastritis duodenitis in } 2 \text { years before } \\
\text { surgery, } \mathrm{n}(\%)\end{array}$ & $1767(11.01)$ & $240(10.58)$ & $1527(11.09)$ & .47 \\
\hline Dyspepsia in 2 years before surgery, $\mathrm{n}(\%)$ & $1837(11.45)$ & $262(11.55)$ & $1575(11.43)$ & .88 \\
\hline $\begin{array}{l}\text { Hiatal hernia in } 2 \text { years before surgery, } n \\
(\%)\end{array}$ & $476(2.97)$ & $71(3.13)$ & $405(2.94)$ & 62 \\
\hline $\begin{array}{l}\text { Gastrointestinal bleed in } 2 \text { years before } \\
\text { surgery, } \mathrm{n}(\%)\end{array}$ & $9(0.00)$ & $2(0.00)$ & $7(0.00)$ & .49 \\
\hline Aspirin use in 1 year before surgery, $\mathrm{n}(\%)$ & $2999(18.69)$ & $412(18.16)$ & $2587(18.78)$ & .48 \\
\hline $\begin{array}{l}\text { Aspirin use in } 3 \text { months before surgery, } n \\
(\%)\end{array}$ & $1900(11.84)$ & $245(10.80)$ & $1655(12.02)$ & .10 \\
\hline NSAID $^{\mathrm{a}}$ use in 1 year before surgery, $\mathrm{n}(\%)$ & $6829(42.57)$ & $986(43.46)$ & $5843(42.42)$ & .36 \\
\hline $\begin{array}{l}\text { NSAID use in three months before surgery, } \\
\mathrm{n}(\%)\end{array}$ & $2342(14.60)$ & $346(15.25)$ & $1996(14.49)$ & .34 \\
\hline Cirrhosis in 2 years before surgery, $\mathrm{n}(\%)$ & $84(0.01)$ & $12(0.01)$ & $72(0.01)$ & .97 \\
\hline Sleep apnea in 2 years before surgery, $\mathrm{n}(\%)$ & $2330(14.52)$ & $346(15.25)$ & $1984(14.40)$ & .29 \\
\hline $\begin{array}{l}\text { Type } 2 \text { diabetes mellitus in } 2 \text { years before } \\
\text { surgery, } \mathrm{n}(\%)\end{array}$ & $5884(36.68)$ & $849(37.42)$ & $5035(36.55)$ & .43 \\
\hline
\end{tabular}




\begin{tabular}{|c|c|c|c|c|}
\hline Variables & $\begin{array}{l}\text { Accumulated } 5 \text { years of } \\
\text { follow-up }(\mathrm{N}=16,043)\end{array}$ & Missing 5-year data $(\mathrm{N}=2269)$ & $\begin{array}{l}\text { Complete 5-year data } \\
(\mathrm{N}=13,774)\end{array}$ & $P$ value \\
\hline $\begin{array}{l}\text { Hypertension in } 2 \text { years before surgery, } \mathrm{n} \\
(\%)\end{array}$ & $8768(54.65)$ & $1270(55.97)$ & $7498(54.44)$ & .17 \\
\hline $\begin{array}{l}\text { Chronic kidney disease in } 2 \text { years before } \\
\text { surgery, } \mathrm{n}(\%)\end{array}$ & $2170(13.53)$ & $319(14.06)$ & $1851(13.44)$ & .42 \\
\hline $\begin{array}{l}\text { Dyslipidemia in } 2 \text { years before surgery, } \mathrm{n} \\
(\%)\end{array}$ & $11,348(70.73)$ & $1844(81.27)$ & $9504(69.00)$ & $<.001$ \\
\hline $\begin{array}{l}\text { Any mental illness in } 2 \text { years before } \\
\text { surgery, } \mathrm{n}(\%)\end{array}$ & $8680(54.10)$ & $1304(57.47)$ & $7376(5.355)$ & $<.001$ \\
\hline $\begin{array}{l}\text { Attendance rate in } 1 \text { year before surgery } \\
\text { (range } 0 \%-100 \%) \text {, mean (SD) }\end{array}$ & $76.70(12.53)$ & $76.50(12.31)$ & $76.70(12.56)$ & .19 \\
\hline $\begin{array}{l}\text { Any inpatient visit } 1 \text { year before surgery, } \mathrm{n} \\
(\%)\end{array}$ & $1081(6.74)$ & $159(7.01)$ & $922(6.69)$ & .58 \\
\hline $\begin{array}{l}\text { Any emergency department visit in } 1 \text { year } \\
\text { before surgery, } \mathrm{n}(\%)\end{array}$ & $3414(21.28)$ & $433(19.08)$ & $2981(21.64)$ & .006 \\
\hline
\end{tabular}

${ }^{\mathrm{a}}$ NSAID: nonsteroidal anti-inflammatory drug.

\section{Understanding the Decisions Between Bariatric Operations}

Table 1 presents pairwise comparisons between VSG and RYGB patients in the ENGAGE CVD cohort to highlight the importance of using state-of-the-art statistical and econometric comparative effectiveness methods to adjust for differences in patient populations between those who receive VSG and those who have RYGB [23-26]. VSG patients, when compared with RYGB patients in the ENGAGE CVD cohort, were younger $(P<.001)$, were more likely to be of a racial and ethnic minority group $(P<.001)$, lost more weight before surgery $(P<.001)$, and had a lower BMI $(P<.001)$; and were less likely to have a BMI $>50 \mathrm{~kg} / \mathrm{m}^{2}$ at the time of surgery $(P<.001)$, had fewer lifetime CVD events $(P=.002)$, and were less likely to be using aspirin before surgery $(P<.001)$.

In addition, VSG patients when compared with RYGB patients in the ENGAGE CVD cohort had lower rates of GERD $(P<.001)$, hiatal hernia $(P=.003)$, sleep apnea $(P<.001)$, T2DM $(P<.001)$, hypertension $(P<.001)$, chronic kidney disease $(P<.001)$, dyslipidemia $(P<.001)$, and mental illness $(P<.001)$ at the time of surgery. Compared with RYGB patients, VSG patients had higher attendance rates for scheduled outpatient visits $(P<.001)$ and lower rates of inpatient $(P<.001)$ service use in the year before surgery.

As part of the process of understanding the decisions between bariatric operations, we conducted a series of meetings over 2 years with bariatric surgeons, patients, and providers about decisions they made between VSG and RYGB. We assembled a set of factors that our stakeholders felt were key determinants of why patients would undergo VSG or RYGB in Table 3. These factors were used to (1) construct propensity models with covariate adjustment and (2) test and select instrumental variables, which use natural variation to mimic random assignment to procedure, for comparative effectiveness analyses. Some of these variables, although important determinants of treatment assignment, were not included in our study because they were not available in the electronic health record. We included these variables in Table 3 because they illustrate the need to use statistical methods that can account for unmeasured confounders in the choice between bariatric operations. Most surgeons and providers indicated that patient preferences for one operation over another would be honored unless the operation they chose was a substantial safety risk for the patient. 
Table 3. Factors considered as determinants in bariatric surgery decisions by a group of health care system stakeholders including patients, providers, and bariatric surgeons in the ENGAGE CVD (Effectiveness of Gastric Bypass versus Gastric Sleeve for Cardiovascular Disease) cohort study.

\begin{tabular}{|c|c|c|c|}
\hline Factor & $\begin{array}{l}\text { Preferred opera- } \\
\text { tion }\end{array}$ & Rationale & $\begin{array}{l}\text { Available in electron- } \\
\text { ic medical record }\end{array}$ \\
\hline Year of surgery & $\begin{array}{l}\text { Depends on } \\
\text { year }\end{array}$ & $\begin{array}{l}\text { Secular trends in surgery were apparent with } \text { RYGB }^{\mathrm{a}} \text { preferred in years before } \\
2011 \text { and VSG }{ }^{\mathrm{b}} \text { preferred after } 2011 .\end{array}$ & Yes \\
\hline Preparation course instructor & $\begin{array}{l}\text { Depends on in- } \\
\text { structor }\end{array}$ & $\begin{array}{l}\text { Preparation course instructors have operation preferences and can communicate } \\
\text { these to the patients and influence their choices. }\end{array}$ & Yes \\
\hline Bariatric surgeon & $\begin{array}{l}\text { Depends on sur- } \\
\text { geon }\end{array}$ & $\begin{array}{l}\text { Surgeons have operation preferences as evidenced by frequency of type of } \\
\text { operation over time. }\end{array}$ & Yes \\
\hline Media consumption & $\begin{array}{l}\text { Depends on } \\
\text { source }\end{array}$ & $\begin{array}{l}\text { Patients may be influenced to choose an operation based on electronic and } \\
\text { other media consumption. }\end{array}$ & No \\
\hline Patient race/ethnicity & VSG & $\begin{array}{l}\text { More non-Hispanic black patients are having VSG compared with RYGB } \\
\text { possibly because it is less surgery, and they will not lose too much weight. }\end{array}$ & Yes \\
\hline $\begin{array}{l}\text { History of cirrhosis and ab- } \\
\text { dominal surgeries }\end{array}$ & VSG & $\begin{array}{l}\text { Some bariatric surgeons believed that RYGB was inappropriate for patients } \\
\text { with a history of cirrhosis and/or abdominal surgeries. }\end{array}$ & Yes \\
\hline $\mathrm{NSAID}^{\mathrm{c}}$ and aspirin use & VSG & $\begin{array}{l}\text { Some bariatric surgeons believed that patients requiring anti-inflammatories } \\
\text { (NSAIDs, aspirin, and steroids) were high risk for surgery regardless of oper- } \\
\text { ation type; however, the highest risk was for RYGB. }\end{array}$ & Yes \\
\hline $\mathrm{BMI}>50 \mathrm{~kg} / \mathrm{m}^{2}$ & VSG & $\begin{array}{l}\text { Some bariatric surgeons believed that much heavier patients had higher com- } \\
\text { plication rates and that patients could be offered VSG to induce weight loss } \\
\text { for a possible later, safer RYGB operation. }\end{array}$ & Yes \\
\hline $\begin{array}{l}\text { Medication-treated mental } \\
\text { health }\end{array}$ & VSG & $\begin{array}{l}\text { Some bariatric surgeons believed that patients requiring medication for mental } \\
\text { health conditions may not do well after RYGB because of changes in absorp- } \\
\text { tion/metabolism after surgery. }\end{array}$ & Yes \\
\hline Poor portion control & VSG & $\begin{array}{l}\text { Some bariatric surgeons believed that if patients were severely obese mostly } \\
\text { because of portion control, VSG would be the most conservative and successful } \\
\text { option. }\end{array}$ & No \\
\hline Complications & VSG & $\begin{array}{l}\text { Most bariatric surgeons felt that VSG resulted in fewer complications than } \\
\text { RYGB and should be the preferred operation to start, unless clearly contraindi- } \\
\text { cated by GERD }{ }^{\mathrm{d}} \text { or gastrointestinal conditions. }\end{array}$ & Yes \\
\hline Sweet eating/craving & RYGB & $\begin{array}{l}\text { Some bariatric surgeons believed that the adverse consequence of dumping } \\
\text { syndrome with RYGB following sweet-eating binges was a good deterrent for } \\
\text { these patients helping them be more successful. }\end{array}$ & No \\
\hline $\begin{array}{l}\text { Type } 2 \text { diabetes mellitus, } \\
\text { hiatal hernia, and GERD }\end{array}$ & RYGB & $\begin{array}{l}\text { Some bariatric surgeons believed that RYGB was better for diabetes remission, } \\
\text { and hiatal hernia and GERD would complicate VSG. }\end{array}$ & Yes \\
\hline
\end{tabular}

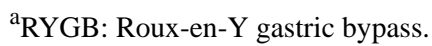

${ }^{\mathrm{b}}$ VSG: vertical sleeve gastrectomy.

${ }^{\mathrm{c}}$ NSIAD: nonsteroidal anti-inflammatory drug.

${ }^{\mathrm{d}}$ GERD: gastroesophageal reflux disease.

\section{Discussion}

\section{Principal Findings}

The ENGAGE CVD cohort was one of the largest sample sizes of real-world bariatric operations, especially VSG, which is now the most common operation performed in the United States [8]. Randomized controlled trials (RCTs) do not have the sample size necessary to properly explore HTE, which can guide subgroups of patients in their decision whether to choose weight loss surgery as a treatment option and then which operation to have $[12,15]$. In addition, the ENGAGE CVD cohort had an excellent long-term follow-up. Nearly $85.86 \%(13,774 / 16,043)$ of patients were members of the health care system 5 years after surgery (see Table 2). Finally, unlike almost any study in the bariatric surgical literature, the ENGAGE CVD cohort was 64\% non-white, providing a rare opportunity to study the effects of bariatric surgery for different racial and ethnic minorities, some of whom have the highest rates of severe obesity in the United States [1]. The ENGAGE CVD cohort has a bariatric surgery patient profile similar to that of the United States in the next 5 to 10 years, as nationwide bariatric practice shifts strongly toward VSG and the United States becomes more racially and ethnically diverse.

\section{Strengths and Weaknesses}

The main weaknesses of the ENGAGE CVD cohort study were that all patients were insured, and although surgery was performed by 23 different surgeons across many settings, including surgeons outside of the health care system, the patients 
in the ENGAGE CVD cohort were cared for primarily within a single integrated health care system. This health care system may not be representative of the care, both preoperatively and postoperatively, that other patients might receive in different kinds of health care settings. In addition, the data were assembled retrospectively from electronic health records that were designed for clinical care and not research. Thus, data were not systematically collected by research personnel at regular intervals. Outcomes were not assessed in a standardized way by research personnel and had to be defined using methods that combined the clinical information available in the electronic health record with clinical stakeholder input about treatment guidelines and practices. There were no mechanisms for obtaining measures from patients who missed appointments and/or disenrolled from the health care system. Despite these limitations, we have shown that data from electronic medical records, such as heights and weights, are valid and suitable for research [21].

In addition, patients were not randomly chosen for surgery from an eligible pool of participants and they were not randomly assigned to operations. This threatens both internal validity (differences between operations could have been because of the assignment process) and external validity (those receiving bariatric operations were not representative of all the patients who were potentially eligible to have these operations). RCTs would be the best statistical design to evaluate the causal efficacy of bariatric surgery for cardiovascular risk reduction (highest internal validity) [27,28]. However, RCTs have poor external validity and cannot answer questions about what will work in an uncontrolled real-world setting or in a population more heterogeneous than the restrictive trial sample that is typically studied [29]. Retrospective observational comparative effectiveness cohort studies such as ENGAGE CVD are better designs for testing how well existing efficacious treatments work for a heterogeneous patient population in an uncontrolled real-world setting.

\section{Conclusions}

The goal of the ENGAGE CVD study was to provide population-based, comprehensive, rigorous evidence for both clinical and policy decision making, informing the choice between RYGB and VSG for overall CVD risk reduction and risk factor remission, as well as safety in a diverse group of patients (racial and ethnic minority). Our findings will be used to provide recommendations to providers and patients about the decision between operations and help prioritize future health policy decisions and research investments in this area.

\section{Acknowledgments}

The ENGAGE CVD cohort study was funded by the National Heart, Lung, and Blood Institute award \#1R01HL130462-01. We would like to thank our patients, providers and other health care system staff who care for them.

\section{Conflicts of Interest}

None declared.

\section{References}

1. Flegal KM, Carroll MD, Kit BK, Ogden CL. Prevalence of obesity and trends in the distribution of body mass index among US adults, 1999-2010. J Am Med Assoc 2012 Feb 1;307(5):491-497. [doi: 10.1001/jama.2012.39] [Medline: 22253363]

2. Loveman E, Frampton GK, Shepherd J, Picot J, Cooper K, Bryant J, et al. The clinical effectiveness and cost-effectiveness of long-term weight management schemes for adults: a systematic review. Health Technol Assess 2011 Jan;15(2):1-182 [FREE Full text] [doi: 10.3310/hta15020] [Medline: 21247515]

3. Ribaric G, Buchwald JN, McGlennon TW. Diabetes and weight in comparative studies of bariatric surgery vs conventional medical therapy: a systematic review and meta-analysis. Obes Surg 2014 Mar;24(3):437-455 [FREE Full text] [doi: 10.1007/s11695-013-1160-3] [Medline: 24374842]

4. Schauer PR, Bhatt DL, Kirwan JP, Wolski K, Aminian A, Brethauer SA, STAMPEDE Investigators. Bariatric surgery versus intensive medical therapy for diabetes - 5-year outcomes. N Engl J Med 2017 Feb 16;376(7):641-651 [FREE Full text] [doi: 10.1056/NEJMoa1600869] [Medline: 28199805]

5. Maciejewski ML, Arterburn DE, van Scoyoc L, Smith VA, Yancy WS, Weidenbacher HJ, et al. Bariatric surgery and long-term durability of weight loss. JAMA Surg 2016 Nov 1;151(11):1046-1055 [FREE Full text] [doi: 10.1001/jamasurg.2016.2317] [Medline: 27579793]

6. Pollack A. New York Times.: New York Times; 2013 Jun 18. AMA Recognizes Obesity as a Disease New York URL: http://www.nytimes.com/2013/06/19/business/ama-recognizes-obesity-as-a-disease.html?hp\& r $=0$ [accessed 2020-02-07] [WebCite Cache ID 78tADaYMI]

7. Faria G. A brief history of bariatric surgery. Porto Biomed J 2017;2(3):90-92. [doi: 10.1016/j.pbj.2017.01.008]

8. Ponce J, Nguyen NT, Hutter M, Sudan R, Morton JM. American Society for Metabolic and Bariatric Surgery estimation of bariatric surgery procedures in the United States, 2011-2014. Surg Obes Relat Dis 2015;11(6):1199-1200. [doi: 10.1016/j.soard.2015.08.496] [Medline: 26476493]

9. Coleman KJ, Huang Y, Hendee F, Watson HL, Casillas RA, Brookey J. Three-year weight outcomes from a bariatric surgery registry in a large integrated healthcare system. Surg Obes Relat Dis 2014;10(3):396-403. [doi: 10.1016/j.soard.2014.02.044] [Medline: 24951065] 
10. Fischer L, Hildebrandt C, Bruckner T, Kenngott H, Linke GR, Gehrig T, et al. Excessive weight loss after sleeve gastrectomy: a systematic review. Obes Surg 2012 May;22(5):721-731. [doi: 10.1007/s11695-012-0616-1] [Medline: 22411568]

11. Switzer NJ, Prasad S, Debru E, Church N, Mitchell P, Gill RS. Sleeve gastrectomy and type 2 diabetes mellitus: a systematic review of long-term outcomes. Obes Surg 2016 Jul;26(7):1616-1621. [doi: 10.1007/s11695-016-2188-y] [Medline: 27103028]

12. Trastulli S, Desiderio J, Guarino S, Cirocchi R, Scalercio V, Noya G, et al. Laparoscopic sleeve gastrectomy compared with other bariatric surgical procedures: a systematic review of randomized trials. Surg Obes Relat Dis 2013;9(5):816-829. [doi: 10.1016/j.soard.2013.05.007] [Medline: 23993246]

13. Yang X, Yang G, Wang W, Chen G, Yang H. A meta-analysis: to compare the clinical results between gastric bypass and sleeve gastrectomy for the obese patients. Obes Surg 2013 Jul;23(7):1001-1010. [doi: 10.1007/s11695-013-0938-7] [Medline: 23595210]

14. Chang SH, Stoll CR, Song J, Varela JE, Eagon CJ, Colditz GA. The effectiveness and risks of bariatric surgery: an updated systematic review and meta-analysis, 2003-2012. JAMA Surg 2014 Mar;149(3):275-287 [FREE Full text] [doi: 10.1001/jamasurg.2013.3654] [Medline: 24352617]

15. Li JF, Lai DD, Lin ZH, Jiang TY, Zhang AM, Dai JF. Comparison of the long-term results of Roux-en-Y gastric bypass and sleeve gastrectomy for morbid obesity: a systematic review and meta-analysis of randomized and nonrandomized trials. Surg Laparosc Endosc Percutan Tech 2014 Feb;24(1):1-11. [doi: 10.1097/SLE.0000000000000041] [Medline: 24487151]

16. Coleman KJ, Huang Y, Koebnick C, Reynolds K, Xiang AH, Black MH, et al. Metabolic syndrome is less likely to resolve in Hispanics and non-Hispanic blacks after bariatric surgery. Ann Surg 2014 Feb;259(2):279-285. [doi: 10.1097/SLA.0000000000000258] [Medline: 24100336]

17. DeMaria EJ, Pate V, Warthen M, Winegar DA. Baseline data from American Society for Metabolic and Bariatric Surgery - designated bariatric surgery centers of excellence using the bariatric outcomes longitudinal database. Surg Obes Relat Dis 2010;6(4):347-355. [doi: 10.1016/j.soard.2009.11.015] [Medline: 20176512]

18. Hutter MM, Schirmer BD, Jones DB, Ko CY, Cohen ME, Merkow RP, et al. First report from the American College of Surgeons Bariatric Surgery Center Network: laparoscopic sleeve gastrectomy has morbidity and effectiveness positioned between the band and the bypass. Ann Surg 2011 Sep;254(3):410-20; discussion 420 [FREE Full text] [doi: 10.1097/SLA.0b013e31822c9dac] [Medline: 21865942]

19. National Institutes for Diabetes and Digestive and Kidney Disorders (NIDDK). Potential Candidates for Bariatric Surgery URL: https://www.niddk.nih.gov/health-information/weight-management/bariatric-surgery/potential-candidates [accessed 2020-02-07]

20. Grundy SM, Stone NJ, Bailey AL, Beam C, Birtcher KK, Blumenthal RS, et al. 2018 AHA/ACC/AACVPR/AAPA/ABC/ACPM/ADA/AGS/APhA/ASPC/NLA/PCNA Guideline on the Management of Blood Cholesterol: A Report of the American College of Cardiology/American Heart Association Task Force on Clinical Practice Guidelines. Circulation 2019 Jun 18;139(25):e1082-e1143. [doi: 10.1161/CIR.0000000000000625] [Medline: 30586774]

21. Arterburn DE, Ichikawa L, Ludman EJ, Operskalski B, Linde JA, Anderson E, et al. Validity of clinical body weight measures as substitutes for missing data in a randomized trial. Obes Res Clin Pract 2008 Dec;2(4):277-281 [FREE Full text] [doi: 10.1016/j.orcp.2008.09.002] [Medline: 19956347]

22. Goff DC, Lloyd-Jones DM, Bennett G, Coady S, D'Agostino RB, Gibbons R, American College of Cardiology/American Heart Association Task Force on Practice Guidelines. 2013 ACC/AHA guideline on the assessment of cardiovascular risk: a report of the American College of Cardiology/American Heart Association Task Force on Practice Guidelines. Circulation 2014 Jun 24;129(25 Suppl 2):S49-S73. [doi: 10.1161/01.cir.0000437741.48606.98] [Medline: 24222018]

23. Basu A. Estimating person-centered treatment (PeT) effects using instrumental variables: An application to evaluating prostate cancer treatments. J Appl Econ (Chichester Engl) 2014;29(4):671-691 [FREE Full text] [doi: 10.1002/jae.2343] [Medline: 25620844]

24. Kent DM, Steyerberg E, van Klaveren D. Personalized evidence based medicine: predictive approaches to heterogeneous treatment effects. Br Med J 2018 Dec 10;363:k4245 [FREE Full text] [doi: 10.1136/bmj.k4245] [Medline: 30530757]

25. Grieve R, O'Neill S, Basu A, Keele L, Rowan KM, Harris S. Analysis of benefit of intensive care unit transfer for deteriorating ward patients: a patient-centered approach to clinical evaluation. JAMA Netw Open 2019 Feb 1;2(2):e187704 [FREE Full text] [doi: 10.1001/jamanetworkopen.2018.7704] [Medline: 30768190]

26. Basu A, Chan KC. Can we make smart choices between OLS and contaminated IV methods? Health Econ 2014 Apr;23(4):462-472 [FREE Full text] [doi: 10.1002/hec.2926] [Medline: 23765683]

27. Salminen P, Helmiö M, Ovaska J, Juuti A, Leivonen M, Peromaa-Haavisto P, et al. Effect of Laparoscopic Sleeve Gastrectomy vs Laparoscopic Roux-en-Y Gastric Bypass on Weight Loss at 5 Years Among Patients With Morbid Obesity: The SLEEVEPASS Randomized Clinical Trial. JAMA 2018 Jan 16;319(3):241-254 [FREE Full text] [doi: 10.1001/jama.2017.20313] [Medline: $\underline{29340676]}$

28. Peterli R, Wölnerhanssen BK, Peters T, Vetter D, Kröll D, Borbély Y, et al. Effect of Laparoscopic Sleeve Gastrectomy vs Laparoscopic Roux-en-Y Gastric Bypass on Weight Loss in Patients With Morbid Obesity: The SM-BOSS Randomized Clinical Trial. J Am Med Assoc 2018 Jan 16;319(3):255-265 [FREE Full text] [doi: 10.1001/jama.2017.20897] [Medline: 29340679] 
29. Sanson-Fisher RW, Bonevski B, Green LW, D'Este C. Limitations of the randomized controlled trial in evaluating population-based health interventions. Am J Prev Med 2007 Aug;33(2):155-161. [doi: 10.1016/j.amepre.2007.04.007] [Medline: 17673104]

\author{
Abbreviations \\ CVD: cardiovascular disease \\ ENGAGE CVD: Effectiveness of Gastric Bypass versus Gastric Sleeve for Cardiovascular Disease \\ GERD: gastroesophageal reflux disease \\ HTE: heterogeneity of treatment effects \\ LIV: local instrumental variable \\ RCT: randomized controlled trial \\ RYGB: Roux-en-Y gastric bypass \\ T2DM: type 2 diabetes mellitus \\ VSG: vertical sleeve gastrectomy \\ Edited by G Eysenbach; submitted 05.06.19; peer-reviewed by A Notarnicola, MA Motamedi; comments to author 21.08.19; revised \\ version received 08.10.19; accepted 16.12.19; published 06.04.20 \\ Please cite as: \\ Coleman KJ, Fischer H, Arterburn DE, Barthold D, Barton LJ, Basu A, Courcoulas A, Crawford CL, Fedorka P, Kim B, Mun E, \\ Murali S, Reynolds K, Suh K, Wei R, Yoon TK, Zane R \\ Effectiveness of Gastric Bypass Versus Gastric Sleeve for Cardiovascular Disease: Protocol and Baseline Results for a Comparative \\ Effectiveness Study \\ JMIR Res Protoc 2020;9(4):e14936 \\ URL: https://www.researchprotocols.org/2020/4/e14936 \\ doi: $10.2196 / 14936$ \\ PMID: $\underline{32249757}$
}

CKaren J Coleman, Heidi Fischer, David E Arterburn, Douglas Barthold, Lee J Barton, Anirban Basu, Anita Courcoulas, Cecelia L Crawford, Peter Fedorka, Benjamin Kim, Edward Mun, Sameer Murali, Kristi Reynolds, Kangho Suh, Rong Wei, Tae K Yoon, Robert Zane. Originally published in JMIR Research Protocols (http://www.researchprotocols.org), 06.04.2020. This is an open-access article distributed under the terms of the Creative Commons Attribution License (https://creativecommons.org/licenses/by/4.0/), which permits unrestricted use, distribution, and reproduction in any medium, provided the original work, first published in JMIR Research Protocols, is properly cited. The complete bibliographic information, a link to the original publication on http://www.researchprotocols.org, as well as this copyright and license information must be included. 